\section{POWERF: A program that computes the power of $F$ tests in fixed-effects ANOVA designs}

\section{RANDALL PARKER and GARY BORICH University of Texas, Austin, Texas 78712}

The power of statistical tests used in behavioral research has been of concern since Cohen's (1962) indictment of abnormal-social psychological research. His findings of minimal power values of statistical tests in published research has been replicated by Brewer (1972) in educational research and by Chase and Chase (1976) in applied psychology.

Perhaps one reason behavioral scientists have been reticent to employ power analysis when designing and reporting research is the lack of a ready technology for accomplishing this goal. This void led Cohen (1969, 1977) to write two books on statistical power analysis that contain extensive tables for power determination. Errors in his 1969 book acknowledged by Cohen (1977) and the unwieldy nature of his tables and their usage led us to write POWERF, based on the earlier work of Borich and Godbout (1974).

To briefly review terminology: Alpha $(\alpha)$ is the probability of committing a Type I error, and $1-\alpha$ is the degree of confidence one has that a statistically significant difference is not due to random error. Beta $(\beta)$ is the probability of committing a Type 11 error. The power of a test is $1-\beta$, or the probability of rejecting the null hypothesis when the sample means come from different populations.

Program POWERF employs an algorithm reported by Cohen (1977) to compute the power of F tests of fixed main effects or $F$ tests of interactions of fixed-effects factors in ANOVA designs. POWERF is written in CDC FORTRAN and is a fast running program. On the dual Cyber 170/750 system at the University of Texas, 36 power determinations were computed in .199 CPU sec.

Input. Four or five values are input, depending on program usage. When estimating the power of a planned experiment, one must input the tabled $F$ value required for significance at any desired $\alpha$ level, the degrees of freedom (df) in the $F$ ratio numerator, the $d f$ in the $F$ ratio denominator, and the estimated effect size (ES).

The ES is a measure of the degree to which the independent variable or treatment of interest affects the dependent variable. In planning an experiment, ES may be estimated from prior research results or the convention may be employed that .10 is a small, .25 is a medium, and .40 is a large ES (Cohen, 1977).
When evaluating a completed study, ES may be computed $\left(E S=n^{2} / 1-n^{2}\right.$, where $n^{2}=$ eta, the correlation ratio, squared). If $E S$ is left blank on the input card, a second card will be read. This card must have either eta squared punched in the first four columns or the sum of squares for the main or interaction effect of interest and the sum of squares total, respectively, punched under a $(4 \mathrm{X}, 2 \mathrm{~F} 13.3)$ format. For a more detailed discussion of ES, see Cohen (1977) and Friedman (1968).

Output. Five values are printed for each set of input values. First, the tabled $F$ value that was input is printed. Next the ES, cell $n$, df numerator, df denominator, and power are printed. The $\mathrm{n}$ value was used by Cohen (1977) in constructing his power tables and will allow one to compare the results of POWERF with Cohen's tabled values.

This comparison in fact was made for a total of 36 problems formed by combinations of $\alpha=.01$ or .05 , $\mathrm{ES}=.10$ or .40 , numerator $\mathrm{df}=1,3$, or 10 , and $\mathrm{n}$ (the average cell size) $=2,10$, or 50 . When the power value was rounded to two places, POWERF produced values that were equal to Cohen's (1977) tabled values in 25 of 36 instances. In all nine cases in which POWERF produced disparate values, they varied only .01 from the tabled values.

Availability. A listing of POWERF may be obtained free of charge to those providing a self-addressed, stamped envelope from Randall Parker, $\mathrm{PhD}$, Department of Special Education, EDB 306, University of Texas, Austin, Texas 78712 .

\section{REFERENCES}

Bonich, G., \& Godbout, R. Extreme groups designs and the calculation of statistical power. Educational and Psychological Measurement, 1974, 34, 663-675.

Brewer, J. On the power of statistical tests in the American Educational Research Journal. American Educational Research Journal, 1972, 9, 391-401.

Chase, L., \& ChASe, R. A statistical power analysis of applied psychological research. Journal of Applied Psychology, 1976, 61, 234-237.

CoHEN, J. The statistical power of abnormal-social psychological research: A review. Journal of Abnormal and Social Psychology, $1962,65,145-153$.

Coнen, J. Statistical power analysis for the behavioral sciences (1st ed.). New York: Academic Press, 1969.

CoHen, J. Statistical power analysis for the behavioral sciences (2nd ed.). New York: Academic Press, 1977.

Friedman, H. Magnitude of experimental effect and a table for its rapid estimation. Psychological Bulletin, 1968, 70, 245-251.

(Received for publication November 28, 1979.) 